\title{
Relationships between Cognitive Functions and Driving Behavior in Parkinson's Disease
}

\author{
Maud Ranchet ${ }^{a}$ Emmanuel Broussolle ${ }^{b, c}$ Alice Poisson ${ }^{b, c}$ \\ Laurence Paire-Ficout ${ }^{\mathrm{a}}$ \\ ${ }^{a}$ IFSTTAR, LESCOT, Fondation Partenariale, Bron, ${ }^{b}$ Université Lyon I, Hospices Civils de Lyon, Hôpital Neurologique \\ Pierre Wertheimer, Service de Neurologie C, and ${ }^{\mathrm{C} C N R S, ~ U M R ~ 5229,}$, Centre de Neurosciences Cognitives, Lyon, \\ France
}

\section{Key Words}

Parkinson's disease $\cdot$ Neuropsychology $\cdot$ Driving $\cdot$

Cognitive function - Executive function - Driving behavior *

Road tests $\cdot$ Driving simulator

\begin{abstract}
Alterations in cognitive functions in Parkinson's disease (PD) have been reported even in mild stages of the disease. These functions may play a role in complex daily activities, such as driving. This article provides an overview on the relationships between cognitive functions and driving behavior in PD in driving simulator and on-road studies. The role of attention, executive functions, visual memory, visuospatial construction and information processing speed is discussed. In driving simulator studies, driving performances were correlated with several neuropsychological measures, especially those of Trail Making Test (TMT), Brixton and Symbol Digit Modalities Test. In on-road studies, TMT, Useful Field Of View and Block Design tests appear as good predictors of driving performances. Most of these tests are also relevant to driving in Alzheimer's disease and traumatic brain injury.
\end{abstract}

Copyright ๑ 2012 S. Karger AG, Basel

\section{Introduction}

The frequency of Parkinson's disease (PD) is expected to increase dramatically in the coming decades due to aging of the population [1]. Although PD is typically identified as a motor disorder, it has also been well established that nonmotor symptoms such as visual, cognitive dysfunctions and increased daytime sleepiness may impact on driving [2-4]. These deficits can appear even in the early stages of the disease $[5,6]$. The most frequently reported cognitive impairments occur in the domains of attention/executive functions, visuospatial abilities [7], psychomotor speed and memory [8]. These functions are all particularly important in novel, dynamic or demanding situations, and most driving scenarios fall into this category.

It is estimated that drivers with PD often continue to drive during the first decade of their illness [9-11]. Some studies have reported decreased driving performances in PD patients compared to controls on driving simulator tests [12-14] and road tests [15-18]. Patients commit more at-fault safety errors [16], especially in the categories of lane observance and stop signs. They also display diffi-

\section{KARGER \\ Fax +4161306 1234 E-Mail karger@karger.ch} www.karger.com
Maud Ranchet, $\mathrm{PhD}$

IFSTTAR

Laboratoire d'Ergonomie et de Sciences Cognitives pour les Transports (LESCOT)

25, Avenue François Mitterrand, Case 24, FR-69675 Bron Cedex (France)

Tel. +334786568 79, E-Mail maud.ranchet@ifsttar.fr 
Fig. 1. Illustration of Michon's model and cognitive functions involved in driving.

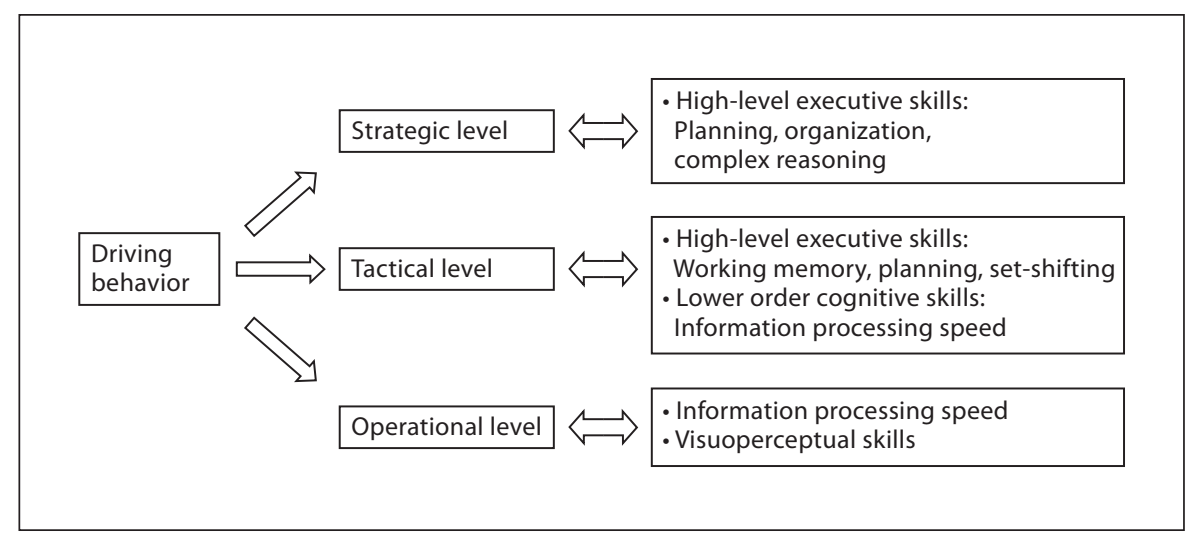

culties in some driving situations, such as urban conditions [15] at intersections or at roundabouts [17]: patients hesitate longer before making a turn, do not accelerate to the proper speed and experience lapses of concentration. They have a decreased awareness of how their driving is affecting others [19] and drive more slowly with higher speed variability during distraction $[10,11]$.

Although many studies showed decreased driving performances in PD patients, there is no clear evidence on real risk of crashes in this population [20,21]. Some authors have shown an increased crash rate in driving simulator studies $[13,22]$ or in retrospective studies, especially those in whom the disease is severe $[23,24]$. However, these studies have methodological bias or limitations such as small sample or lack of control group. Conversely, a cross-sectional study including a population-based sample of 1051 drivers aged 65 years or more [25] showed that PD patients did not report more crashes than drivers without neurological diseases. Nevertheless, the sample size for PD was small. A recent prospective study on 106 PD drivers and 130 controls revealed no difference between groups in crash risk [21]. One explanation might be that patients would stop driving before having crashes [21]. Indeed, PD patients stopped driving earlier than controls [21]. Driving cessation is either decided by the drivers themselves [1], their family or their practitioners [26]. To better understand the reasons for driving cessation or increased crashes in PD, several groups investigated the factors that may contribute to poor driving performances $[1,16,27,28]$. It appears that the role of cognitive factors in PD is a major issue and could be more crucial than motor, visual functions, daytime sleepiness and medication effects $[11,15,17,29,30]$.

The present paper provides a narrative overview on the relationships between cognitive functions and driv- ing behavior in PD. We first develop the theoretical basis of driving behavior and its relevance to PD. Then, we examine the correlations between neuropsychological performances and driving abilities in PD both in simulator and on-road studies. Finally, we briefly compare the main findings observed in PD with other neurological diseases, such as Alzheimer's disease (AD), traumatic brain injury or stroke. We conclude with some clinical recommendations and future research perspectives.

\section{Theoretical Basis of Driving Behavior and Its Relevance to PD}

Driving is a complex activity which requires various visual, motor and cognitive abilities. In most driving situations, the driver has to use perception, process information and to make a number of decisions very quickly. In order to understand driving activity better, Michon et al. [31] have distinguished three levels of driving behavior. Strategic level behaviors include actions such as choosing the route and time of travel. Tactical level behaviors involve actions such as adapting following distance and adjusting speed. Operational level behaviors include second-to-second driving behaviors such as maintaining lane position and reacting to obstacles. These operational behaviors are heavily time-pressured. As shown in figure 1, these levels imply several cognitive domains.

The Michon's model is relevant to PD. Indeed, literature shows that PD patients have difficulties in these three driving behavior levels. For strategical level, they have difficulties while performing a distraction or navigation task $[10,11]$. Regarding tactical level, PD drivers have problems in reversing, negotiating traffic light con- 
trolled intersections, adapting driving to changing road conditions or changing lane $[12,15,17,19]$. As referred to operational level, patients have an increased driving reaction time, a delayed deceleration or difficulties in maintaining a constant lateral position [12, 14, 32-34].

\section{Relationships between Cognitive Functions and Driving Behavior in PD}

Most reports have compared PD patients' driving performances to those of matched healthy controls. Some studies are conducted on driving simulators, which involve tactical and operational level behaviors; other studies use instrumented vehicles in real on-road situations, which involve both of these levels but also strategic level behavior. In this type of experiment, PD patients are always evaluated while on medication, when they are feeling their best.

\section{Studies on Driving Simulators}

Approach using the driving simulator may offer the advantage of accurately assessing driving behavior in a controlled and reproducible environment. It provides a safe environment for the patient and the evaluator and great associations between simulator and on-road performance have been reported [35]. Table 1 summarizes studies focusing on the relationships between cognitive functions and driving behavior using driving simulator in PD patients. The four main research papers on this topic are those of Stolwyk et al. [12, 30,33] and from our group [36].

In the three Stolwyk studies, the same population was used. Their first study examined the impact of cueing on driving behaviors around traffic signs and curves in PD [12]. In this experiment, the driver was warned of upcoming obstacles. Results showed that patients exhibited difficulties using internal cues (use of information previously memorized from the map) to regulate driving behavior around traffic signs and curves. Instead of using internal cues, PD drivers were more reliant on external cues (road signs which warn upcoming obstacles) to regulate driving behavior [12]. One of the possible explanations could be that internal guiding demands more attentional resources than external cues. This result suggests that external cues, such as driving assistance systems might be useful for PD drivers. Further research should consider these findings in the future.

The second research of Stolwyk et al. [30] investigated correlations between neuropsychological test performances and driving simulator behaviors. Authors showed that the impairment of key executive skills (Trail Making Test-B (TMT-B) and Brixton) compromises tactical level driving behaviors in patients with PD. Moreover, an impairment of lower order cognitive skills such as information processing speed (Symbol Digit Modalities Test SDMT - oral version), attention to detail (picture completion task) and basic visuoperception (Judgement Line Orientation (JLO)) involves difficulties in driving behaviors at the operational level [30]. These authors recommend the TMT-B, SDMT and Brixton as potential screening tools for driving competency assessment in people with PD.

The third study of Stolwyk et al. [33] investigated the impact of a concurrent task on driving performance. Main results showed that patients, as controls adapted their driving behavior when the concurrent task was present. However, PD patients performed significantly less well the concurrent task than controls. As suggested by the authors, it is likely that PD drivers sacrificed concurrent task performance to maintain driving ability. Findings of these three studies support the hypothesis of decreased attentional resources in PD patients [10, 33]. However, PD drivers were able to maintain appropriate driving behavior especially in low or moderate attentional demanding conditions which is an important result for road safety.

Recently, low-level executive functions, particularly the updating of information in working memory and mental flexibility in patients with mild-to-moderate PD compared to controls have been investigated by our group both in neuropsychological and simulated driving contexts [36]. The main finding was an impairment of updating function in early stages of PD whereas there were no differences in flexibility tasks between the two groups. It also appeared that updating task on driving simulator have a greater impact on driving performances (mean speed and speed variability) for both groups, suggesting that updating task is more demanding than flexibility task. Another contribution of this study was to reveal the usefulness of TMT in PD driver assessment which is in accordance with many other studies $[2,10,30,37]$.

In summary, main findings of studies using driving simulator highlight potential tools for PD driver assessment. Among these tools, TMT, Brixton test and SDMT which assess executive functions and/or information processing speed are relevant.

\section{On-Road Studies}

Road studies are assumed to be the most ecological tests of driving competence. Six main experiments have 


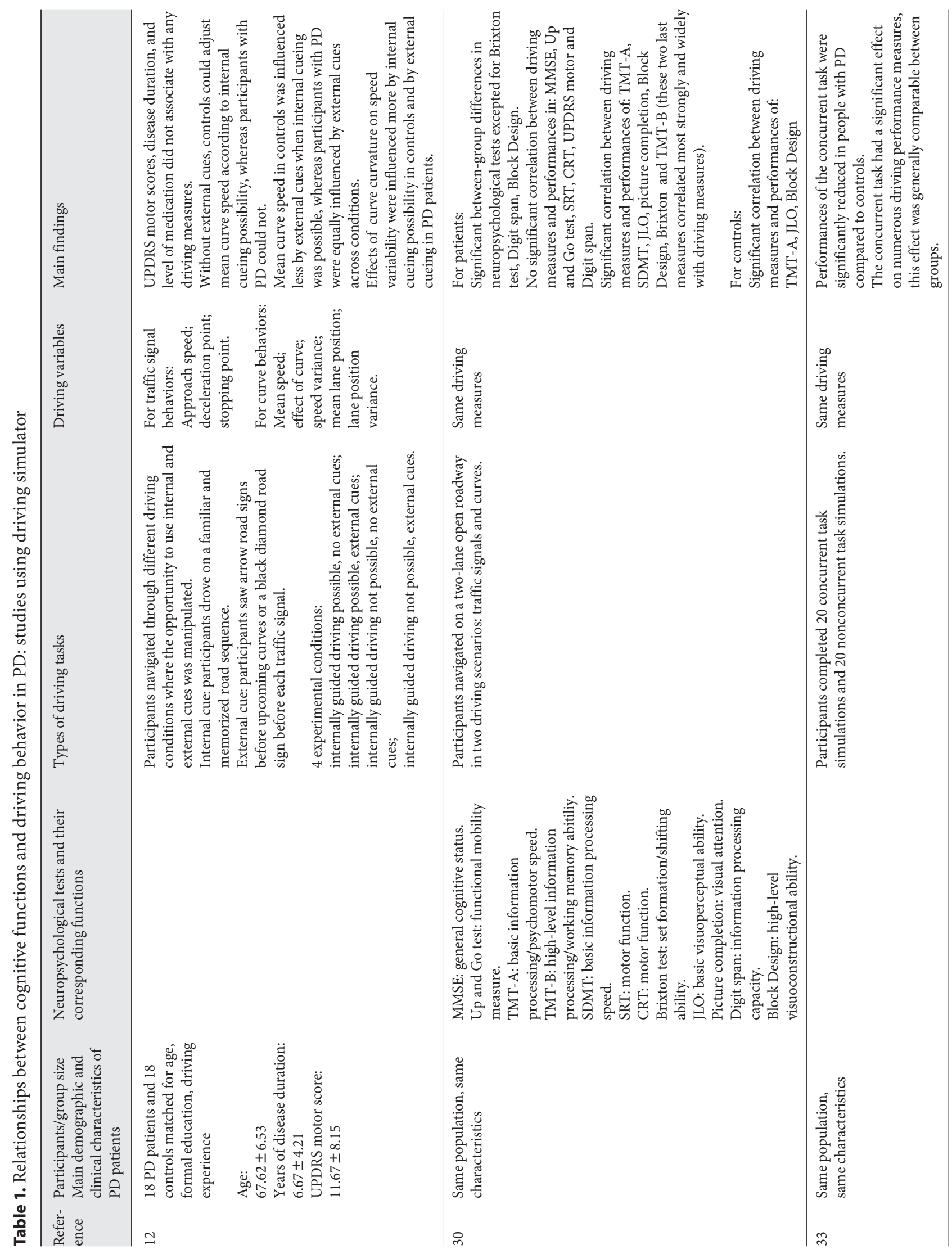




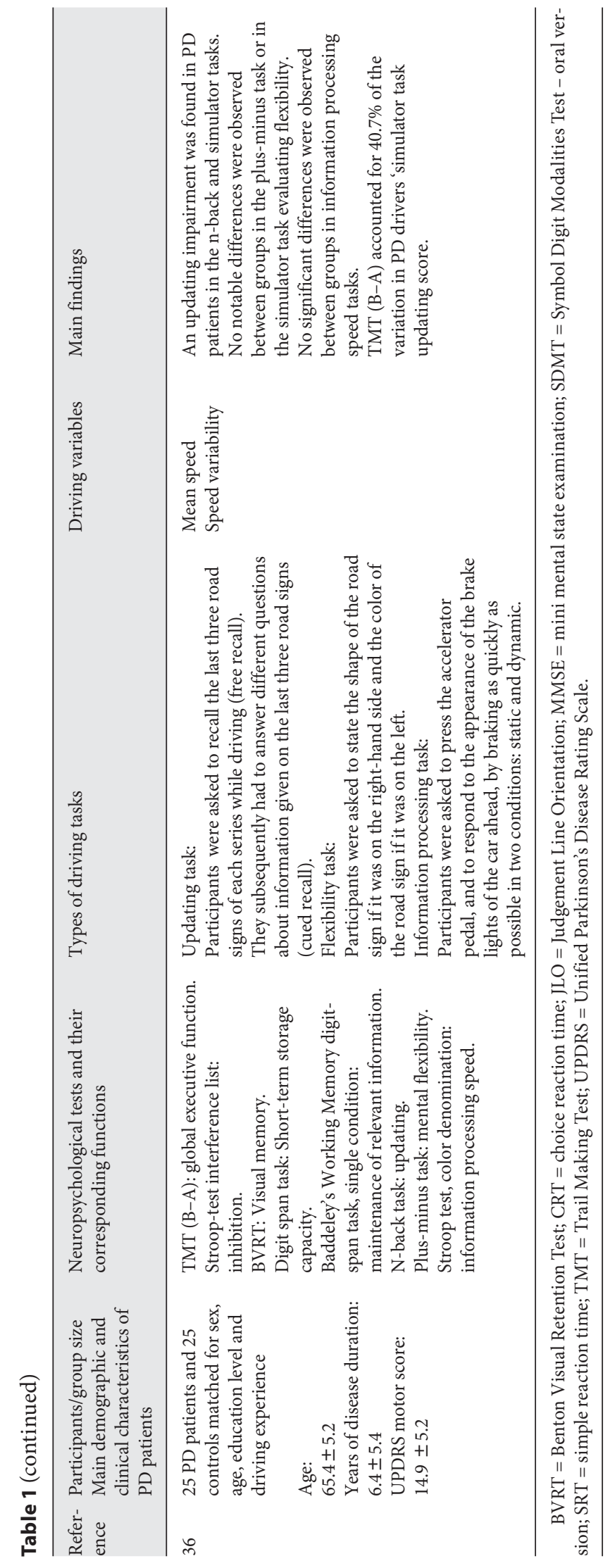

investigated correlations between cognitive performances and driving abilities in real on-road situations in PD patients compared to matched healthy controls $[10,11,15$, $16,18,19]$ (table 2). One of the purposes of these reports was to find methods of assessing the driving ability of PD patients.

In the Heikkila et al. [15] study, measures of laboratory tests correlated to a high degree with driving performances in PD patients. These authors suggest that tests of vigilance and concentration, visual perception, choice reaction time and information processing in a complex situation should be included in the assessment of PD drivers [15]. In a larger sample, decline in visual attention (Useful Field Of View (UFOV)), visual construction (Block Design), visual memory and general cognition appeared to be significant predictors of total error counts within the PD group [16]. In the Worringham et al. [18] study which investigated the predictors of driving in $\mathrm{PD}$, only 1 of 6 cognitive tests, the SDMT, correlated significantly with the average driving safety score. This test, performed verbally, was considered in this study as a measure of short-term memory and attention switching. Performances at this test were also significantly better for those who passed than those who failed the on-road test [18]. In another study, SDMT performance was also correlated with driving measures [38]. Amick et al. [19] showed that neuropsychological composite score, considered as a measure of executive functions, is associated with performances in the tactical domain. This is consistent with the idea that key executive skills compromise tactical driving behavior [30]. It has been suggested that neuropsychological measures requiring rapid responding, visual spatial cognition and executive functioning are most useful for distinguishing safe from marginal drivers [19]. However, since no control group is available in this latter study, it is not possible to determine which neuropsychological tests can discriminate PD patients from healthy control drivers [19].

As is well known, driving is an activity in which the individual drives in a continually changing environment while thinking or speaking at the same time. Other research has also been conducted in order to investigate the role of cognitive functions in driving activity while drivers performed a secondary task. Uc et al. [10] showed that PD patients responded more heterogeneously to distraction than controls. According to the authors, the association of increased steering variability with better function on cognitive, vision, and motor tests might represent, under this experimental setting, a compensatory effort to maintain vehicle control despite distraction. In addition, 


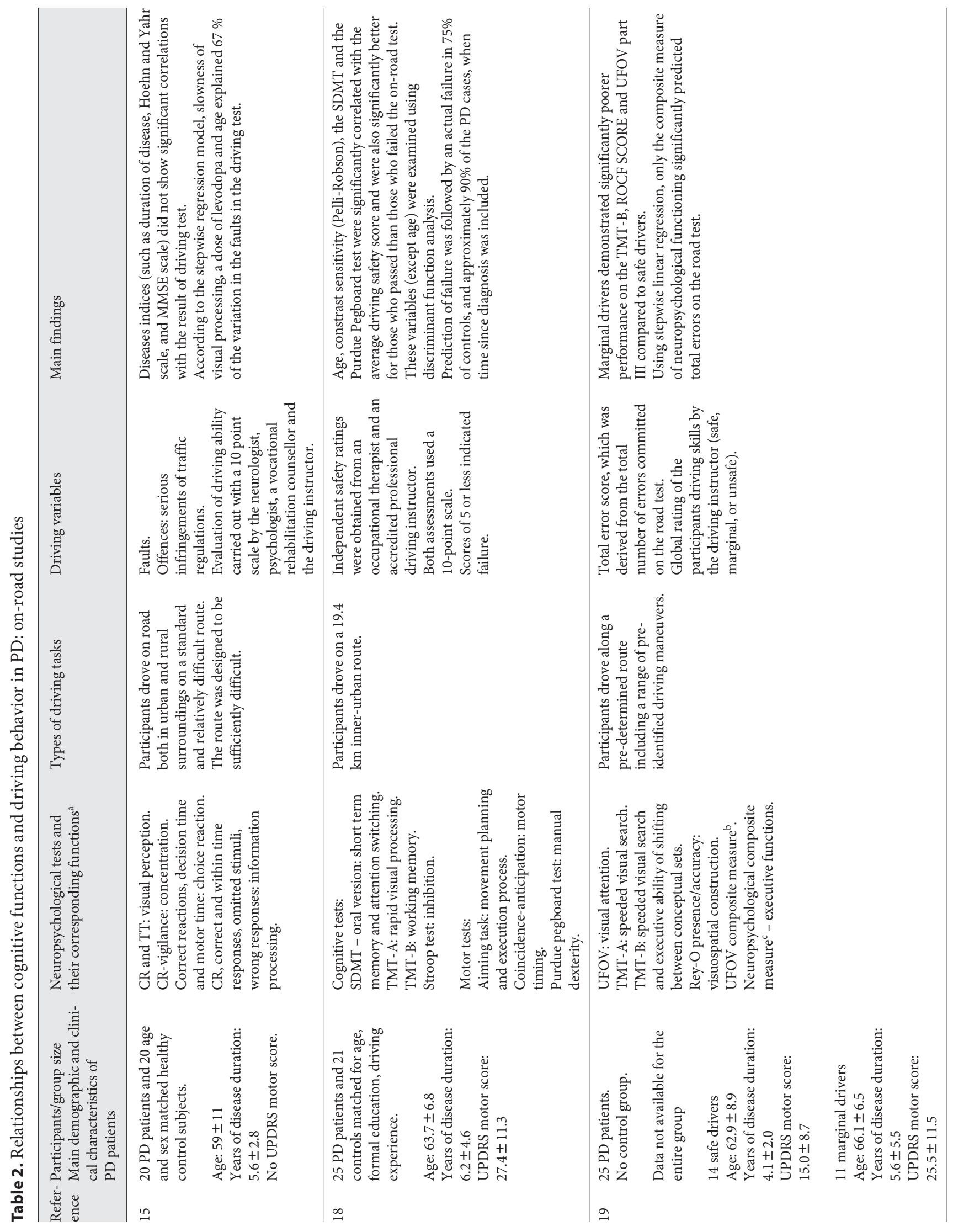




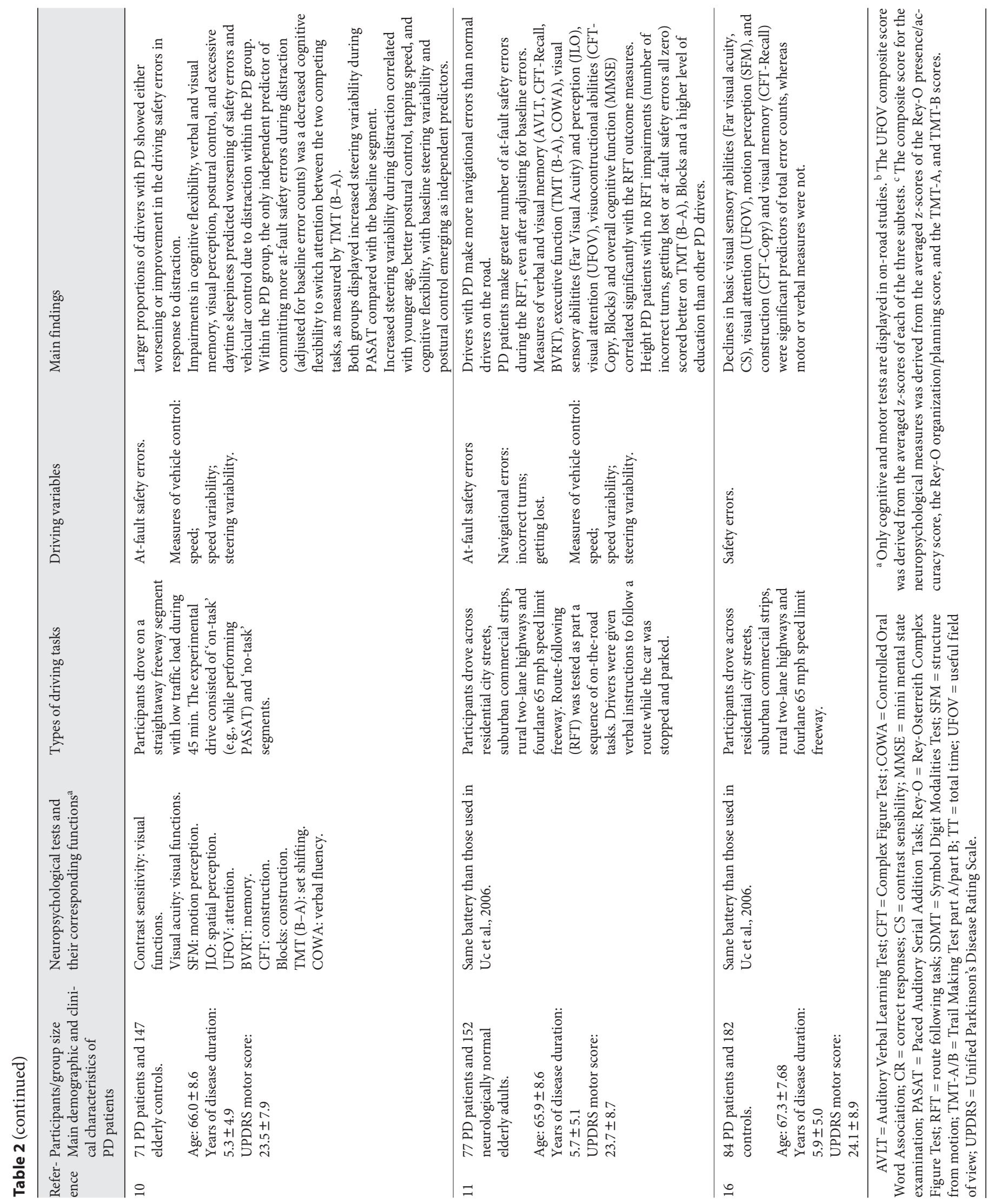


the TMT (B-A) performance was the only independent predictor of safety errors during distraction. Accordingly, in another study performed by the same team, PD drivers with no impairments in Route Following Task scored better on TMT (B-A). These two on-road studies confirm the usefulness of TMT for clinicians to predict driving performances in PD drivers. Importantly, clinical indices such as disease duration, motor score or Hoehn et Yahr scale have not been shown as reliable predictors of driving performances in most studies suggesting that they cannot be used alone as relevant indicators of safe driving (table 2) $[15,17,26,39]$.

In summary, main findings of studies on-road suggest that TMT, SDMT, UFOV and Block Design tests are good predictors of driving or have strong correlations with driving performances in patients with PD.

\section{Comparison with Other Neurological Diseases}

The question that arises is the following: Are the neuropsychological tests used in PD drivers specific to this pathology or are they common to other neurological diseases?

First, we shall examine the results found in driving studies in patients with $\mathrm{AD}$, which is a neurodegenerative disease as PD (for review, see [40]). While there is no consensus about real crash risk in PD, there is clear evidence that $\mathrm{AD}$ patients have an increased risk of crashes compared to age-matched controls [41]. Several studies attempted to determine the neuropsychological tests that predict unsafe driving in $\mathrm{AD}$ patients. For instance, Uc et al. [37] showed in $61 \mathrm{AD}$ drivers and 115 elderly controls that unsafe outcomes were predicted by tests of visual perception (JLO, Complex Figure Test (CFT), Block Design), speed of processing and attention (UFOV), memory, visuospatial/constructional abilities (CFT-Copy CFT-Recall), mobility and executive functions (TMT-B). Interestingly, tests used to predict driving in $\mathrm{AD}$ patients are similar to those used in PD patients. However, AD patients exhibit severe deficits in all tests whereas PD patients with mildto-moderate stages have more specific and discrete alterations especially in executive and visuospatial functions [8].

Second, in traumatic brain injury patients, the most important lesions are located in the frontal lobes, which are involved in executive functions. Additionally, driving difficulties in this population have been associated with impaired attention, concentration, processing speed, visual memory and visual-spatial skills (for review, see [42]). Accordingly, as in PD, TMT-B, SDMT or Block Design are reported as good predictors of unsafe driving in traumatic brain injured patients [42].

Cognitive Functions and Driving Behavior in PD
Third, in stroke patients, no uniform method exists to evaluate post-stroke patients' driving ability since more focal deficits are concerned. More than hemiplegia, visual performances are a major issue. This is particularly the case with homonymous visual field defects especially because many stroke patients are unaware of the field loss. Thus, the assessment of driving safety is significantly different in stroke compared to PD patients (for review, see [43]).

To summarize, similar neuropsychological tests may be used to assess driving ability in various neurological conditions. It is not surprising because of their multicomposite nature, as is the case for driving activity. This applies particularly for $\mathrm{PD}, \mathrm{AD}$ and traumatic brain injury $[40,42,44]$.

\section{Conclusions}

This review aimed to investigate cognitive predictors of driving ability in PD drivers. Although further work is required, it is an important goal to help clinicians or researchers to determine cognitive tests that could be used as a means of evaluating driving ability in PD patients and identify unsafe drivers.

\section{Clinical Recommendations}

The published evidence on driving performance in PD patients supports the following recommendations for $\mathrm{PD}$ driver assessment:

- First, assess main domains which can affect driving such as executive, visuospatial and information processing speed functions.

- Second, use a battery of neuropsychological tests which have been shown as the best predictors of driving performance in PD patients such as TMT, UFOV, SDMT - oral version and Brixton.

- Third, do not use clinical indices alone, such as duration of disease, Hoehn and Yahr scale and mini mental state examination scale as reliable indicators of driving $[15,39]$.

These recommendations are, however, not strong enough to provide for any of these neuropsychological tests a cut-off below which authorities would prevent PD patients from driving.

\section{Future Research}

As shown above, there is little literature about driving and PD compared with other neurological diseases such $\mathrm{AD}$ or traumatic brain injury. Further research could be

Eur Neurol 2012;68:98-107 
addressed regarding crash risk and driving cessation in $\mathrm{PD}$, and using naturalistic driving conditions to investigate the real road safety risk of this population. As outlined by Klimkeit et al. [39], a lot of work is needed to better advise health professionals. Additional research is also required to determine the degree of impairment for which drivers can be considered as unsafe. Furthermore, a cognitive training program involving executive, atten- tional functions relevant to the driving activity could be worthwhile to rehabilitate PD patients with driving impairments.

\section{Disclosure Statement}

None of the authors have a conflict of interest.

\section{References}

1 Cubo E, Martinez Martin P, Gonzalez M, et al: What contributes to driving ability in Parkinson's disease. Disabil Rehabil 2010;32: 374-378.

- Uc EY, Rizzo M, Anderson SW, Sparks JD, Rodnitzky RL, Dawson JD: Impaired visual search in drivers with Parkinson's disease. Ann Neurol 2006;60:407-413.

3 Schlesinger I, Ravin PD: Dopamine agonists induce episodes of irresistible daytime sleepiness. Eur Neurol 2003;49:30-33.

$\checkmark 4$ Amick MM, D'Abreu A, Moro-de-Casillas ML, Chou KL, Ott BR: Excessive daytime sleepiness and on-road driving performance in patients with Parkinson's disease. J Neurol Sci 2007;252:13-15.

5 Dubois B, Pillon B: Cognitive deficits in Parkinson's disease. J Neurol 1997;244:2-8.

-6 Suzuki K, Miyamoto T, Miyamoto M, Okuma Y, Hattori N, Kamei S, Yoshii F, Utsumi $\mathrm{H}$, Iwasaki Y, Iijima M, Hirata K: Excessive daytime sleepiness and sleep episodes in Japanese patients with Parkinson's disease. Neurol Sci 2008;271:47-52.

7 Bradley VA, Welch JL, Dick DJ: Visuospatial working memory in Parkinson's disease. J Neurol Neurosurg Psychiatry 1989;52:12281235.

-8 Muslimovic D, Post B, Speelman JD, Schmand B: Cognitive profile of patients with newly diagnosed Parkinson disease. Neurology 2005;65:1239-1245.

-9 Singh R, Pentland B, Hunter J, Provan F: Parkinson's disease and driving ability. J Neurol Neurosurg Psychiatry 2007;78:363-366.

$\checkmark 10$ Uc EY, Rizzo M, Anderson SW, Sparks JD, Rodnitzky RL, Dawson JD: Driving with distraction in Parkinson disease. J Neurol 2006; 67:1774-1780

-11 Uc EY, Rizzo M, Anderson SW, Sparks JD, Rodnitzky RL, Dawson JD: Impaired navigation in drivers with Parkinson's disease. Brain 2007;130:2433-2440.

-12 Stolwyk RJ, Triggs TJ, Charlton JL, Iansek R, Bradshaw JL: Impact of Internal versus external cueing on driving performance in people with Parkinson's disease. Mov Disord 2005;20:846-857.
13 Zesiewicz TA, Cimino CR, Malek AR, Gardner N, Leaverton PL, Dunne PB, Hauser RA: Driving safety in Parkinson's disease. Neurology 2002;59:1787-1788.

14 Madeley P, Hulley JL, Wildgust H, Mindham RHS: Parkinson's disease and driving ability. J Neurol Neurosurg Psychiatry 1990;53:580582.

15 Heikkila VM, Turkka J, Korpelainen J, Kallanranta T, Summala H: Decreased driving ability in people with Parkinson's disease. J Neurol Neurosurg Psychiatry 1998;64:325330.

16 Uc EY, Rizzo M, Johnson AM, Dastrup E, Anderson SW, Dawson JD: Road safety in drivers with Parkinson disease. Neurology 2009;73:2112-2119.

17 Wood JM, Worringham C, Kerr G, Mallon K, Silburn P: Quantitative assessment of driving performance in Parkinson's disease. J Neurol Neurosurg Psychiatry 2005;76:176180.

18 Worringham CJ, Wood JM, Kerr GK, Silburn P: Predictors of driving assessment outcome in Parkinson's disease. Mov Disord 2006;21:230-235.

19 Amick MM, Grace J, Ott BR: Visual and cognitive predictors of driving safety in Parkinson's disease patients. Arch Clin Neuropsychol 2007;22:957-967.

20 Homann CN, Suppan K, Homann B, Crevenna R, Ivanic G, Ruzicka E: Driving in Parkinson's disease - a health hazard? J Neurol 2003;250:1439-1446.

21 Uc EY, Rizzo M, Johnson AM, Emerson JL, Liu D, Mills ED, Anderson SW, Dawson JD: Real-life driving outcomes in Parkinson disease. Neurology 2011;76:1894-1902.

22 Uc EY, Rizzo M, Anderson SW, Dastrup E, Sparks JD, Dawson JD: Driving under lowcontrast visibility conditions in Parkinson's disease. Neurology 2009;73:1103-1110.

23 Dubinsky RM, Gray C, Husted D, Busenbark K, Vetere-Overfield B, Wiltfong D, Parrish D, Koller WC: Driving in Parkinson's disease. Neurology 1991;41:517-520.
24 Adler G, Rottunda S, Bauer M, Kuskowski M: Driving cessation and Alzheimer's Disease: Issues confronting patients and family. Am J Alzheimer's Dis Other Dement 2000; 15:212-216.

25 Lafont S, Laumon B, Helmer C, Dartigues JF, Fabrigoule C: Driving cessation and self-reported car crashes in older drivers: the impact of cognitive impairment and dementia in a population-based study. J Geriatr Psychiatry Neurol 2008;21:171-182.

-26 Cordell R, Lee HC, Granger A, Vieira B, Lee AH: Driving assessment in Parkinson's disease - a novel predictor of performance? Mov Disord 2008;23:1217-1222.

27 Uitti RJ: Parkinson's disease and issues related to driving. Parkinsonism Relat Disord 2009;15(suppl 3):S122-S125.

28 Vaux LM, Ni R, Rizzo M, Uc EY, Andersen GJ: Detection of imminent collisions by drivers with Alzheimer's disease and Parkinson's disease: a preliminary study. Accid Anal Prev 2010;42:852-858.

29 Grace J, Amick MM, D’Abreu A, Festa EK, Heindel WC, Ott BR: Neuropsychological deficits associated with driving performance in Parkinson's disease and Alzheimer's disease. J Int Neuropsychol Soc 2005;11:766775 .

-30 Stolwyk RJ, Charlton JL, Triggs TJ, Iansek R, Bradshaw JL: Neuropsychological function and driving ability in people with Parkinson's disease. J Clin Exp Neuropsychol 2006; 28:898-913.

31 Michon JA: A critical view of driver behavior models: what do we know, what should we do?; in Evans LA, Schwing R (eds): Proceedings of the International Symposium on Driver Behavior and Traffic Safety. General Motors Research Laboratories. New-York, Plenum Press, 1985, pp 485-520.

32 Lings S, Dupont E: Driving with Parkinson's disease: a controlled laboratory investigation. Acta Neurol Scand 1992;86:33-39.

- 33 Stolwyk RJ, Triggs TJ, Charlton JL, Moss S, Iansek R, Bradshaw JL: Effect of a concurrent task on driving performance in people with Parkinson's disease. Mov Disord 2006;21: 2096-2100. 
-34 Radford KA, Lincoln NB, Lennox G: The effects of cognitive abilities on driving in people with Parkinson's disease. Disabil Rehabil 2004;26:65-70.

$\checkmark 35$ Lee HC, Cameron D, Lee AH: Assessing the driving performance of older adult drivers: on-road versus simulated driving. Accid Anal Prev 2003;35:797-803.

>36 Ranchet M, Paire-Ficout L, Marin-Lamellet C, Laurent B, Broussolle E: Impaired updating ability in drivers with Parkinson's disease. J Neurol Neurosurg Psychiatry 2011;82: 218-223.

-37 Uc EY, Rizzo M, Anderson SW, Shi Q, Dawson JD: Unsafe rear-end collision avoidance in Alzheimer's disease. J Neurol Sci 2006; 251:35-43.
38 Lafont S, Marin-Lamellet C, Paire-Ficout L, Thomas-Anterion C, Laurent B, Fabrigoule C: The Wechsler Digit Symbol Substitution Test as the best predictor of unsafe driving in Alzheimer disease and normal aging. Dement Geriatr Cogn Disord 2010;29:154-163.

39 Klimkeit EI, Bradshaw JL, Charlton J, Stolwyk R, Georgiou-Karistianis N: Driving ability in Parkinson's disease: current status of research. Neurosci Biobehav Rev 2009;33: 223-231.

40 Dubinsky RM, Stein AC, Lyons K: Practice parameter: risk of driving and Alzheimer's disease (an evidence-based review): Report of the Quality Standards Subcommittee of the American Academy of Neurology. Neurology 2000;54:2205-2211.
1 Dubinsky RM, Williamson A, Gray CS, Glatt SL: Driving in Alzheimer's disease. J Am Geriatr Soc 1992;40:1112-1116.

42 Hopewell CA: Driving and traumatic brain injury; in Schultheis MT, DeLuca J, Chute DL (eds): Handbook for the Assessment of Driving Capacity. New York, Elsevier, 2009, pp 71-94.

43 Poole D, Chaudry F, Jay WM: Stroke and driving. Top Stroke Rehabil 2008;15:37-41.

44 Etienne V: Executive Functions and Driving. Study in Normal Ageing and Alzheimer's disease/in Lyon. Lyon, University of Lyon, 2008. 